\title{
REQUIREMENTS FOR PLANNING TO DEVELOP TEACHING STAFF AT MEDICAL COLLEGES IN VIETNAM
}

\section{Tuan Van Bui}

\section{Article History}

Received: June 17, 2019

Accepted: July 30, 2019

Published: September 30, 2019

\section{Keywords}

Teaching staff, development, planning, plans, medical colleges

\author{
Ha Dong Medical College, Vietnam \\ Email: tuanbuivan50@yahoo.com
}

\section{INTRODUCTION}

These days, in the context of the need to improve the quality of the country's health-care human resources training, the Communist Party has paid special attention to the development of teaching staff at the higher education institutions to train health-care human resources in general and medical colleges in particular. At the same time, it was determined that planning and developing teaching staff is one of the most important and decisive issues, affecting the development direction, as well as the quantity, quality and structure of the teaching staff in each school compared to the requirements of the practice. Therefore, in the Resolution of the $8^{\text {th }}$ Central Conference $\left(11^{\text {th }}\right.$ session) on fundamental and comprehensive innovation of education and training, the Party has highlighted: "planning to train and develop teachers and educational managers in association with the needs of socio-economic development, national security, defense and international integration. It is necessary to standardize the teaching staff according to educational level and training level". From the above issues, planning to develop teaching staff at medical colleges is definitely one of the urgent and critical issues in the current context.

This article explores the requirements when developing master plans to foster teaching staff at medical colleges to meet current requirements and missions.

\section{LITERATURE REVIEW}

There have been a number of studies in the world and in Vietnam on planning to promote teaching staff at healthcare human resource training institutions in general and at medical colleges in particular. There are several typical papers as follows:

The management to promote teaching staff at medical schools is one of the factors of paramount importance with great impact on the quality of health service human resources all over the world. In 1983, Nigel C. H. Stott wrote the book entitled "The Refuge: Ethics, practices and problems". In this book, the author indicates that the ultimate aim of health care is to improve patients' physical and mental health so that they are able to recover from their health problems soon. To effectively fulfill this task, the author emphasizes that each nation should improve the quality of human resources for health service; also, the author affirms the crucial role of teaching staff at training schools for healthcare human resource and doctors in all aspects: taking care of patients, practicing clinic and researching medicine.

In the article namely "Training and developing healthcare human resources in some countries and lessons for Vietnam", the author Chung, N. D. (2008) states that all medical universities in the United States pay much attention to promote teaching staff; in particular, to the policies to attract high quality human resources, especially scientists and experts to work permanently at schools in terms of accommodation, commuting, payment and working conditions.

In the paper "Strategic orientation for training and developing health care workers", Dip, N. V. (1999) emphasizes: "It is vital to improve the quality of medical schools of which the building of their managing and teaching staff plays the key role". In the paper "The current situation of teaching and the need for economic training of medical-economic teachers at Pharmaceutical and medical Universities in Vietnam", Anh, T. T. and Minh, H. V. 
(2012) specify in one certain aspect of the quality of medical teachers at Medical Universities presently. They point out: "Vietnam is in short of medical economic teachers with good qualifications such as doctorate's degrees/ second degree specialist (accounting for only 25\%); the current medical economic teachers are not trained equally making up a small proportion but teaching the most assigned periods compared to other groups of teachers.

In the field of teacher development at medical colleges in our country, Hieu, P. M. (2010) publishes the study entitled "Practical and theoretical basis for teacher development at medical colleges meeting the demand of training healthcare human resources in the new period". In this paper, the author thoroughly analyses and addresses the theoretical issues on teacher development at medical colleges presenting the current situation, limitations and shortcomings and proposing 7 different solutions to promote teaching staff development at medical colleges presently.

However, there have been no studies researching systematically and thoroughly both theoretically and practically the issue of planning and developing the teaching staff at medical colleges presently.

\section{RESEARCH METHODS AND RESULTS}

\subsection{Research methods}

- Theoretical research methods includes analysis, synthesis, generalization and systematization of problems through the study of theoretical documents, monographs, scientific articles within the research scope.

- Empirical research method:

+ Summary of experience: Researching documents, summarizing reports related to the teaching staff of current medical colleges, especially in terms of the current situation and making comments on the quality of the teaching staff.

+ Pedagogical observation: Conducting observation with teaching staff at medical colleges during the process of performing their tasks.

+ Sociological investigation and expert consultancy.

\subsection{Research results}

\subsubsection{The concept of planning and developing teaching staff at medical colleges at present}

The planning and development of teaching staff at medical colleges is the development of an educational institution's human resources, a change in the quantity and quality of human resources in terms of physical capacities, intellectual resources, skills, knowledge and spirit along with the process of creating progressive changes in the structure of human resources. In the most general way, planning to develop teaching staff of medical colleges basically means developing high-quality human resources in the medicine field. The planning and development plan of the team is to emphasize the internal development of human resources in terms of quantity, quality and organizational structure. On the other hand, team development is always associated with developing quality and capacity of each individual through personal development in the team.

Thus, planning to develop the teaching staff of medical colleges with the above content essentially refers to the issue of developing high-quality human resources and social aspects of human resources in the medical industry. The above developmental views are the basis for determining the theoretical background of the planning and management for the development of teaching staff of medical colleges at present. Planning for the development of teaching staff at medical colleges is the process of organizing, controlling and influencing of managers on the teaching staff to develop the teaching staff in terms of quality, quantity and structure in line with the requirements of the school's education and training tasks, promoting the strengths of the individual and the teaching staff as a whole.

\subsubsection{A number of requirements for planning to develop teaching staff at medical colleges at present}

Firstly, schools should effectively train their managing staffs at all levels to raise the awareness of the position, the role and the meaning of the plan to develop the teaching staff. This is a critical requirement in planning and developing of teaching staff in schools. The reason is that only on the basis of this work, can the subjects including principals, leaders, managers of faculties, staff managing organizations have the correct and deep awareness about positions, roles and meanings of planning to develop teaching staff. At the same time, every stage, every step, every content of planning to develop teaching staff would be as scheduled, well-organised and in a direct and scientific manner with the aim to help schools build master plans and plans to develop teaching staff with practicality and high feasibility.

In order to fulfill this mission, in the coming time, medical colleges need to focus on educating managers at all levels about the position and role of lecturers in deciding the quality of training as well as in the process of school 
development through distributing and informing about the Party and State's Documents, Resolutions, Directives, such as Law on Education, Law on Higher Education, Party's $12^{\text {th }}$ National Delegation Congress Document, Resolution No. 29/NQ-TW "On fundamental and comprehensive innovation in education, serving industrialization and modernization in a socialist-oriented market economy during international integration". Educating the position, the role and the meaning of planning to develop the teaching staff in ensuring that the school's staff in any stage are fully capable in terms of structures to fulfill all the human resource training tasks set by the healthcare sector. This content is expressed through studying and mastering the documents related to the development of teaching staff such as regulations on the number of lecturers at healthcare human resource training schools; regulations on working regime of lecturers; the project of training lecturers with doctoral degrees for universities and colleges in the 20102020 period promulgated by the Ministry of Education and Training; regulations related to the allowance regime, working experience for teachers of the Government, branch allowance regimes issued by the Ministry of Health and regulations in formulating human resource master plans.

In addition, each school needs to focus on educating, raising the awareness of responsibility, functions and duties as well as favourable conditions, short-term and long-term challenges related to teaching staff development at the school such as: Training and retraining lecturers, regimes and policies for remuneration of lecturers through thoroughly informing about the resolutions of the Party organizations at all levels in schools; school development strategy in each specific period.

Secondly, each school needs to renovate the perception and the way to build a plan to develop the teaching staff. In developing teaching staff at medical colleges, masterplanning is considered a specific step of the guidelines and development strategies of the schools, so it needs a long-term orientation. At the same time, it also directly realises the development strategies in practice; strengthens the scientific and practical basis of formulating plans and implementing them in the long-term orientation; strengthens the scientific and practical basis of decision-making and planning policies to serve the formulation of development plans. Planning is considered a step of implementing the masterplan, following the masterplan's orientation and being short-term. It directly goes into detailed and specific issues to maximise the effectiveness of the process of organizing the development plan of teaching staff. Therefore, masterplanning must always be associated with the plan for managing and developing teaching staff. Therefore, it is critical to renovate the perception and manner of masterplanning and planning to develop teaching staff. To achieve this goal, schools need to focus on the following specific contents:

- Renovating the perception of developing master plans for lecturers' development: Schools must have proper awareness about the position and role of developing master plans and plans for teaching staff development; this should be considered a regular task the most important content in the development of teaching staff.

- Renovating the way of masterplanning and planning the development of teaching staff: When formulating masterplans and plans, the higher levels shall take subordinate plans and plans as a basis for their own master plans and plans. Specifically, each school bases on master plans to develop teaching staff approved by management agencies at all levels; plans of each specialized department, characteristics of the teaching staff at the school to set up their school masterplans and plans. The Faculties shall base on that school masterplan and plans and combine with the characteristics of their own faculty members to formulate the faculty masterplan and plans to develop their teaching staff. Each lecturer must develop their own plan in accordance with the faculty masterplan.

The plan of teaching staff development at each school must include the following points: criteria to appoint lecturers in different positions; criteria for lecturers to attend training programs to improve their qualifications in accordance with the disciplines and faculties and the estimated number of lecturers who can meet those standards; objectives, quantity and specific cases of retirement according to the regime; recruiting plans including quantity, timing and methods, etc. The content of the plan must show interest and priority to young lecturers, who are dedicated to the profession, having good qualities, competence and basic training to further training at higher levels, to train and introduce to become future managers and leaders at all levels.

In addition to the above-mentioned issues, schools need to renovate the plan implementation. To be more specific, in the process of organizing the implementation of the plan, the school's leaders, specialized departments and faculties must intensify the inspection of the performance of lecturers under their authority to grasp the developments, quality, career development direction of each lecturer to be able to continue to accomplish and adjust the plan to develop teaching staff, especially in identifying potential lecturers to send for further training and future appointment to managerial and leadership positions. 
Thirdly, each school needs to establish a procedure of developing a plan to develop the teaching staff to ensure the principles and in accordance with the requirements of developing the teaching staff at their school.

Establishing the procedure of developing a plan for developing teaching staff is the main responsibility of the Schools' Party Committees, Boards of Director, and Principals. Therefore, in order to fulfill this request, Principals should base on the school's strategy and vision to identify goals, set school development tasks in the immediate years and orient them in the following years (normally in a period of 5 years and 10 years); direct the relevant organisations and departments to conduct surveys, analyse the characteristics of the school, the context and current situation, the capabilities of the school lecturers, etc. Then, a plan to develop the teaching staff in terms of quantity, quality and structure to fulfill the identified goals and tasks will be developed. In the masterplan and specific plans, it is necessary to include the expected contents such as objectives, tasks and responsibilities of the departments; basic criteria, number of sources of lecturers in each faculty; timing and conditions to ensure the training and retraining of lecturers, especially those expected to be leading cadres in the school, etc. At the same time, it is necessary to directly instruct the specialized organisations to guide the faculties and divisions in formulating a plan to develop teaching staff in the faculty based on the school's plans. During the implementation process, the Principal must regularly and closely monitor and grasp the activities of organizing the implementation of the plans of the relevant departments, promptly detect the shortcomings and limitations to make timely corrective decisions.

The procedure of developing a plan to develop teaching staff at schools is carried out according to the following basic steps:

Step 1: Preparation. This is the first step in developing a plan to develop the teaching staff, including assigning tasks to the planning forces; determining goals and missions to be achieved; time to complete the plan; necessary logistics for relevant parties to develop plans, etc.

Step 2: Assessment of the current situation of teaching staff and forecasting objective and subjective factors affecting the development of lecturers at school. The planning parties formulate plans to conduct surveys and questionnaires to evaluate the situation (quantity, quality, structure of lecturers at the current school...). At the same time, it is necessary to forecast factors affecting the development of faculty members based on the goals and strategies for school development such as: Development trend of healthcare human resources; motivation and career development trends of the teaching staff; development direction of the school; requirements on the quality of teaching staff from which to identify specific objectives and targets to ensure the compatibility with the practical situation and to confirm the high feasibility and attainability of those goals and targets.

Step 3: Clearly identifying specific goals and targets, including determining the targeted quantity and quality of teaching staff in the whole school at each specific time and stage; specific targets and quantities for each intended post of appointment and each person to send for training and fostering, etc.

Step 4: Identifying specific contents in the plan, including defining each content, specific requirement in the whole plan for teaching staff development such as: content, form, method of training and retraining of teaching staff; specific content of recruiting teaching staff (time, recruitment profiles, recruitment subjects, etc.).

Step 5: Finalizing faculty development plans and approving. After the contents of the lecturer development plan have been developed, the human resource department of each school revises the layout and wording of the plan and finalizes the contents via written documents to report to the Principal. The Principal will review and approve the plan.

Step 6: Organising the implementation of the approved plan. After the plan is approved, it will be deployed to organizations, faculties to finalize the plans at the faculties. At the same time, it will be organized to deploy in accordance with the contents of the verified master plan.

Fourthly, promoting the roles of organizations and faculties in developing a plan to develop teaching staff.

The Personnel Department is the agency that directly advises the Schools' Party Committees and Boards of Directors on the development of lecturers including the task of developing a plan for faculty development. In order to fulfill this requirement, the Department of Human Resources needs to thoroughly grasp and implement the orientation and guidance of the higher-level organizing agencies, the direction of the school principal; promoting the sense of responsibility of each department and individual managers in carrying out the assigned tasks; providing specific and detailed orientations and instructions, details and requirements on the work of developing the teaching staff for each specialized faculty. On the other hand, based on the planning of the faculties, the Department of Human Resources compares and contrasts with the school's proposed plan, promptly adjusts and accomplishes the plan so that it is close 
to reality. Subsequently, it should be synthesized and reported to the Principal for review and approval of the plan for developing teaching staff in the school.

As for faculties, in fact, the Dean of each faculty must base on the orientation and guidance of the superiors in developing a plan to develop the teaching staff of the school, the specific situation of the faculty (redundance or shortage of teaching staff); assessment of quality, competency, and development direction of the teaching staff. On the other hand, it is necessary to direct and guide the lecturers in the faculty to develop their own plans in all aspects, such as needs, career development direction, the process of self-studying and self-fostering in order to improve their qualities and professional capacity. In developing the plan, the Dean of the Faculty must pay special attention to the quantity and quality of lecturers so that it can fulfill the Faculty's teaching tasks in accordance with the development trend of the school. The content of the plan must clearly indicate the source of the lecturers' titles, quantity of lecturers to recruit or reduce by year and period, quantity and list of lecturers to send for training and fostering, etc.

\section{DISCUSSION AND CONCLUSION}

Developing the plan to promote teaching staff is an important and necessary task for the schools at present time. To accomplish this mission, schools are required to thoroughly understand and fulfill the above basic requirements. As a result, each school would be able to establish a suitable path in developing teaching staff, ensuring that this team is always sufficient and appropriate in terms of quantity, quality and structure so as to successfully fulfill every educational and training task of schools in the current time.

\section{REFERENCES}

Anh, T. T. - Minh, H. V. (2012). The current situation of teaching and the need for economic training of medical-economic teachers at Pharmaceutical and Medical universities in Vietnam. Journal of Practical Medicine, 4, 132-136.

Bao, D. Q. - Vinh, N. T. (2011). Schools Management. Publishing House of Vietnam Education.

Chung, N. D. (2008). Training and developing healthcare human resources in some countries and lessons for Vietnam. Journal of Development and Integration, 12, 14-16.

Congress (2005). Education Law 2005, revised and edited in 2009. National Political Publishing House (Vietnam).

Dip, N. V. (1999). Strategic orientation for training and developing health care workers. Journal of Policy and Medical Sociology, 4, 9-12.

Duc, M. D. (chief-editor, 2007). Organising and managing healthcare service. Hanoi Publishing House.

Hieu, P. M. (2010). Theoretical and empirical basis for teacher development at medical colleges, meeting the demands of training human resources for healthcare service in the new times. Dissertation on Education Management, Hanoi National University.

Microsoft (2015). Applying information technology in teaching and learning. Vietnam Education Publishing House.

Nigel C. H. Stott (1983). The Refuge: Ethics, Practices and Problems. In "Primary Health Care: Bridging the Gap Between Theory and Practice", Springer, London, 93-103.

Tan, T. N. (2012). Development of education and training - Human and talents resources: International experiences. Publishing House of Politics - Public Administration.

Thao, H. M. - Truyen, H. T. (2006). Legal background of renovation of state management and education management. Publishing House of Hanoi National University.

The Central Executive Committee (2013). Resolution No. 29-NQ/TW dated November 4, 2013 on fundamental and comprehensive innovation in education, serving industrialization and modernization in a socialist-oriented market economy during international integration.

The Centre of Human Resource Development (2002). From strategy for education development to policy for human resource development. Education Publishing House.

The Prime Minister (2012). Decision No. 771/QD-TTg dated June 13, 2012 Approving the 2011-2020 education development strategy.

The Prime Minister (2017). Decision No. 117/QD-TTg dated January 25, 2017 on Project "Promoting the application of information technology into the management and support for teaching, learning and scientific researching, contributing to improving the quality of education and training in the 2016-2020 period, with vision up to 2025 ".

Tuan, B. V. (2019). Management of teacher development at Medical Colleges in Hanoi city. Publishing House for Labour and Society. 